\title{
PARENTAL ATTACHMENT, SMARTPHONE ADDICTION AND STRESS AMONG UNDERGRADUATE STUDENTS
}

\author{
Tan Pey Shyan ${ }^{1}$ \\ Department of Human Development and Family Studies, \\ Faculty of Human Ecology, Universiti Putra Malaysia. \\ (Email: xiaopei_1010@live.com) \\ Zarinah Arshat ${ }^{2}$ \\ Department of Human Development and Family Studies, \\ Faculty of Human Ecology, Universiti Putra Malaysia. \\ (Email: zarinah_upm@upm.edu.my)
}

Received date: 11-07-2019

Revised date: $24-07-2019$

Accepted date: 26-07-2019

Published date: 15-09-2019

To cite this document: Tan, P. S., \& Arshat, Z. (2019). Parental Attachment, Smartphone Addiction and Stress among Undergraduate Students. International Journal of Education, Psychology and Counseling, 4 (32), 149-163.

DOI: $10.35631 / \mathrm{IJEPC} .4320015$

\begin{abstract}
This study aims to determine the relationships between parental attachment, smartphone addiction and stress among undergraduate students. By using a multi-stage cluster random sampling technique, a total of 400 respondents were involved in this study. Inventory of Parent and Peer Attachment-Revised Mother, Father and Peer Attachment version was used to measuring parental attachment. Smartphone Addiction Scale-Short Version was used to measure smartphone addiction and Perceived Stress Scale-10 was used to measure stress. As expected, mother attachment, father attachment, and smartphone addiction were significantly correlated with stress. Meanwhile, there were no significant differences in smartphone addiction and stress between male and female undergraduate students. This study concluded that parental attachment and smartphone addiction were significant in influencing the stress level of undergraduate students. By understanding the impact of parental attachment and smartphone addiction towards stress among undergraduate students, it helped to enhance the understanding of sources of stress in order to promote effective stress management.
\end{abstract}

Keywords: Father Attachment, Mother Attachment, Smartphone Addiction, Stress

\section{Introduction}

A research conducted in Malaysia showed that 13.9\%, 51.5\% and 12.9\% of the students have clinically significant depression, anxiety and stress respectively (Radeef, Faisal, Ali \& Ismail, 2014). Most Malaysian students suffer from excessive stress. One reason is the cultural 
pressure to graduate with good grades because graduating with good grades could give them an opportunity to get a better career (Ramli, Alavi, Mehrinezhad \& Ahmadi, 2018). Malaysian students unable to regulate themselves effectively when encountering high levels of academic stress (Ahmadi, Mustaffa, Haghdoost \& Alavi, 2014).

Stress is defined as "a condition or feeling experienced when a person perceives that demands exceed the personal and social resources the individual is able to mobilize" (The American Institute of Stress, 2017). Tertiary education is considered as a highly stressful period and stressful environment that can bring negative effects to the psychological and physical wellbeing of university students (Othman, Farooqui, Yusoff \& Adawiyah, 2013). Excessive stress can cause physical and mental health problems, reduce students' self-esteem and affect students' academic performance (Niemi \& Vainiomaki 1999). The amount of stress experienced by individuals determined by their abilities to cope with stressful events and situations (D'Zurilla \& Sheedy, 1991).

Parental attachment is "a relational bond existing between a parent or guardian and child" (Rabbani, Kasmaienezhadfard \& Pourrajab, 2014). Parental attachment is established through proximity, safety and security that is offered by a parent or guardian and is experienced by a child; however, parental attachment is expressed through varying levels of trust, communication, and alienation (Schnyders, 2012). Parents play an important role in the formation of individual's attachment styles. An individual's perception about whether the caretaker is available when the need arises or whether he or she is responsive causes the differences in attachment styles. Secure attachment style is developed when parents behave sensitively and consistently toward child's needs, whereas children whose parents do not provide child's needs emotionally and physically develop insecure attachment style. It is said that children with secure attachment style are self-confident and they have secure attachment behaviours in their social and close relationships. On the other hand, children with insecure attachment style see themselves more worthless and do not trust people easily. They also have problems in personal and interpersonal relationships (Dogan, Gur, Sener \& Cetindag, 2012). Students face a lot of new challenging experiences attending university. This is because many students are on their own for the first time and they are in a completely new setting that requires them to establish new relationships. Individuals tends to move away from attachment relationships with their parents as they grow older (Dogan et al., 2012). Therefore, a good time to study attachment is during university.

A smartphone is "a mobile phone that performs many of the functions of a computer, typically having a touch screen interface, internet access, and an operating system capable of running downloaded applications" (Oxford Dictionaries, n.d.). Smartphone addiction is defined as a habitual drive or compulsion to continue to use mobile phone repeatedly despite its negative effects on one's well-being (Roberts \& Pirog III, 2012). Smartphone addiction is different from addictions such as alcohol or drugs. Alcohol or drugs are substance addiction while smartphone addiction is behavioral addiction (Van Deursen, Bolle, Hegner \& Kommers, 2015). In behavioral addictions, the individual is not addicted to a substance but the behavior or feeling caused by the relevant action (Alavi et al., 2012). There is an increasing dependence on smartphones among young adults and university students. Many young adults cannot envision an existence without their smartphones (Roberts, Yaya \& Manolis, 2014). Smartphone use during class is common for many university students. The constant use of smartphone in class may disrupt the students' ability to engage in class activities actively and their learning experience, which could eventually lead to academic stress due to the lack of preparation of students for assessments (Thomas, 2016). Besides that, 
excessive usage of mobile phone may impact the social relationships of students, such as the relationship between students and their peers and the relationships with their professors (Roberts et al., 2014). In brief, it is crucial to understand the variables that predict stress among university students so that intervention and prevention of stress management can be conducted. This is to ensure the overall well-being of undergraduate students.

\section{Literature Review}

\section{Relationship between Parental Attachment and Stress}

There are some studies show that there is a negative relationship between attachment and stress (Howard \& Medway, 2004; Vogel \& Wei, 2005; McCarthy, Lambert, \& Moller, 2006). Although there is a negative relationship between attachment and stress, but the researchers highlighted that it was a correlational, not causative relationship. Howard and Medway (2004) conducted a study to examine how attachment affects the ways students cope with stress. The results showed that students' attachment security was positively associated with family communication and negatively associated with avoidance behaviors when encountering stressful situations. In contrast, attachment insecurity was positively related with avoidant behaviors like drug and alcohol use when encountering stress.

Vogel and Wei (2005) indicate that university students with insecure attachment denied that they experienced stress. Insecurely attached students are unlikely to seek help. On the other hand, securely attached students acknowledge stress and are more likely to seek help. Thus, insecurely attached students might not receive needed assistance and their performance might reflect the lack of resistance (Vogel \& Wei, 2005).

Low parental attachment is positively correlated with stress symptoms and stress-produced emotions among four-year university students (McCarthy et al., 2006). Secure attachment is associated with lower levels of stress symptoms and stress-produced emotions than insecure attachment. As secure attachment increases, stress symptoms and stress-produced emotions decrease (McCarthy et al., 2006).

\section{Relationship Between Smartphone Addiction and Stress}

There are some researchers have suggested that having constant access to smartphone might be stressful, because of a felt obligation to always be available to one's virtual social network (Thomée, Dellve, Härenstam \& Hagberg, 2010). Thomée et al. (2010) propose that the pressure to be always available is associated with greater smartphone use, and this pressure is associated with feelings of guilt, stress and depression. There are various mechanisms that lead to the development of problematic or addictive smartphone use have been proposed, which are habitual use and checking one's smartphone, excessive reassurance checking and the fear of missing important information or events (Elhai, Dvorak, Levin \& Hall, 2017). This model of problematic smartphone use has been influenced by theoretical models of internet addiction, and these mechanisms are assumed as the route through which smartphone use can cause psychological distress such as stress, anxiety and depression (Elhai et al., 2017).

Some studies suggest that smartphone use is associated with reduced stress (Kline \& Liu, 2005; Toda, Ezoe \& Takeshita, 2014); whereas there are some other studies suggest that smartphone use is associated with increased stress (Thomée, Härenstam \& Hagberg, 2011; Yun, Kettinger, \& Lee, 2012). Besides that, there are other studies that suggest stress leads to smartphone use (Wang, Wang, Gaskin \& Wang, 2015; Jeong, Kim, Yum \& Hwang, 2016), whereas others suggest that smartphone use may cause stress (Murdock, 2013). In short, the 
literatures on smartphone use and stress show mixed results. Besides that, there is no comprehensive theory or explanation has been tested for why smartphones are associated to the feelings of stress or anxiety (Vahedi \& Saiphoo, 2018).

\section{Gender Differences in Smart Phone Addiction and Stress}

There are many studies have addressed the gender differences in smartphone addiction, but there is no consensus on which group is at the higher risk as the results are mixed. As one of the most cited and popular study regarding mobile phone addiction, Bianchi and Philips (2005) state that there is no significant difference in mobile phone addiction between males and females. They conclude that gender does not predict overall use of the mobile phone because both genders have embraced mobile phone technology equally. There is another study with similar findings. The main purpose of the study conducted by Sahin, Ozdemir, Unsal and Temiz (2013) was to determine the mobile phone addiction level in university students. From the findings, they found that there is no significant difference between females and males with regard to mobile phone addiction level. Furthermore, Nassehi, Arbabisarjou, Jafari, Ghasemi and Najafi (2016) conducted a study to assess the relationship of Internet addiction with excessive dependence on cell phone, depression, anxiety, and stress in the students of Bam University of Medical Sciences. The results revealed that there is no significant difference between male and female students on the addiction of mobile phone.

A study conducted by Hakoama and Hakoyama (2011), which aimed to evaluate the impact of cell phone use on social networking and development among college students. The results revealed that females significantly spent more time on the cell phone than males, which make females more prone to cell phone addiction. The findings of this study is congruent with another study conducted by Andone et al. (2016). Andone et al. (2016) carried out a study to assess how gender and age affect smartphone usage, and the results showed that females spent more time using their phones compared to males. Van Deursen, Bolle, Hegner and Kommers (2015) conducted a study to investigate the role of process and social oriented smartphone usage, emotional intelligence, social stress, self-regulation, gender, and age in relation to habitual and addictive smartphone behavior. The results revealed that females use their smartphones more to maintain their social relationships, gossip more on the phone than males do and have more conversations than males (Van Deursen et al., 2015). In another study conducted by Balakrishnan and Raj (2012), which aimed to examine the role of mobile phones among urbanized Malaysian youth, especially among university students, the results of gender analysis revealed that female students use their mobile phones more to socialize, gossip and as a safety device.

Dusselier, Dunn, Wang, Shelley and Whalen (2005) performed a study to examine anxiety and factors that influence stress. The results revealed that many personal, health, academic and environmental variables are able to predict the stress of students. They also discovered that in general, the female students experience stress more frequently in the university setting than the male students did (Dusselier et al., 2005). Furthermore, Brougham, Zail, Mendoza and Miller (2009) conducted a study to assess the stress, sex differences and coping strategies of college students. The results showed that female college students reported a higher overall level of stress and greater use of emotion-focused coping strategies than male students (Brougham et al., 2009). The findings of this study is consistent with the research conducted by Matud (2004). Matud (2004) conducted the study to examine gender differences in stress and coping styles. The results also indicated that female suffer more stress than man and their coping style is more emotion-focused. 


\section{Research Questions}

According to relations among variables, the present study addressed the following research questions:

1. Are there any relationships between parental attachment and smartphone addiction with stress among undergraduate students?

2. What are the differences in parental attachment, smartphone addiction and stress between male and female undergraduate students?

3. What factors are uniquely predictors of stress among undergraduate students?

\section{Research Objectives}

Based on the above discussion, the general objective of this study is to determine the relationships between parental attachment, smartphone addiction and stress among undergraduate students. While for specific objectives of this study as follow:

1. To explore the relationships between student background (age and years of education) and parent background (age, years of education and monthly income) with stress among undergraduate students.

2. To determine the relationships between parental attachment, smartphone addiction and stress among undergraduate students.

3. To compare differences in smartphone addiction and stress between male and female undergraduate students.

4. To determine what factors uniquely predict stress among undergraduate students.

\section{Methodology}

\section{Research Design}

The present study was a quantitative research and survey method has been used in this study using a self-administered questionnaire was prepared to collect the data. This study was also a cross-sectional research because a large group of undergraduate students were observed at one point in time to provide data. Besides that, this study was categorized as correlational research because it was conducted to determine the extent of the existence of a relationship between parental attachment and smartphone addiction, whether both variables significantly related to stress among undergraduate students. The correlational designs allow researchers to determine the extent which a variable corresponds to other variables, as well as to determine what factors uniquely predict stress among students. The direction and strength of association between the variable in this study were identified.

\section{Sample}

A total of 400 Universiti Putra Malaysia (UPM) undergraduate students were recruited in this study using multistage cluster random sampling technique. Four faculties out of six teen faculties in UPM were randomly selected using lottery method. There were 268 female students and 132 male students. The average age of respondents was 22.98 years old with standard deviation of 1.55 . Among 400 respondents, $180(45.00 \%)$ of them were staying in campus, $120(30.00 \%)$ of them were staying out of campus and $100(25.00 \%)$ of them were staying with the family. 


\section{Measures}

\section{Parental Attachment}

Inventory of Parent and Peer Attachment-Revised (IPPA-R) - was used to measure parental attachment in this study (Armsden \& Greenberg, 1987). The scale consist of 25 items in order to assess the quality of communication, feelings of trust, and degree of alienation that individuals perceive in their parental and peer relationships. IPPA-R has three parent and peer subscales, which are trust, communication and alienation. This instrument is a selfreported questionnaire with a five-point Likert scale $(1=$ Almost Never or Never True to $5=$ Almost Always or Always True). Negatively stated items are reversely scored before calculations. Subscale scores are computed by summing the item responses in each section. In the current study, only parent section (Mother and Father Attachment) is taken into consideration. Examples of items are "I feel my mother/father does a good job as my mother/father", "My mother/father accepts me as I am" and "My mother/father trusts my judgment". For the revised version, The Cronbach's alpha correlation coefficient was 0.87 for mother attachment, 0.89 for father attachment and 0.92 for peer attachment (Armsden \& Greenberg, 1987). This shows that IPPA-R scale has high internal consistency reliability. In another study, the Cronbach's alpha correlation coefficient for the IPPA-R ranged from 0.74 to 0.89 (Zhang, Zhang, Zhang, Wang \& Hung, 2011). In this study, the Cronbach's Alpha for mother attachment was 0.92 , while for father attachment was 0.95

\section{Smartphone Addiction}

Smartphone Addiction Scale - Short Version (SAS-SV) is a scale to examine smartphone addiction (Kwon, Kim, Cho \& Yang, 2013). It contains 10 items with a six-point Likert-scale (1: "strongly disagree", 2: "disagree", 3: "weakly disagree", 4: "weakly agree", 5: "agree", and 6: "strongly agree") based on self-reporting. The rating of the scale is based on how much each statement relates to participants. The scores are to total up to be measured, it can range from 10 to 60. The cut-off value for males is 31 and for females is 33 . For those who scored higher than the cut-off values are considered as high-risk for smartphone addiction. Examples of items are "Having a hard time concentrating in class, while doing assignments, or while working due to smartphone use", "Feeling impatient and fretful when I am not holding my smartphone" and "Missing planned work due to smartphone". The internal consistency reliability and concurrent validity of SAS-SV were certified with Cronbach's alpha correlation coefficient of 0.911 (Kwon et al., 2013). This scale has been used in various recent researches across culture, such as in the study by Lopez-Fernandez (2017) which showed Cronbach's alpha correlation coefficient of 0.88 and 0.90 for Spain and Belgium respectively, and study by Noyan, Darcin, Nurmedov, Yilmaz and Dilbaz (2015) which showed a Cronbach's alpha correlation coefficient of 0.867 . In this study, the Cronbach's Alpha for the scale was 0.88

\footnotetext{
Stress

Perceived Stress Scale-10 (PSS-10) (Cohen, Kamarck, \& Mermelstein, 1983) was used to assess the degree to which people perceive their lives as stressful. The rating of the scale is based on how often participants have found their lives unpredictable, uncontrollable, and overloaded in the last month. PSS-10 contains 10 items and uses a five-point Likert-scale ranging from 0 (Never) to 4 (Very Often). Four positively stated items (items 4, 5, 7 and 8) are reversely scored $(0=$ very often, $1=$ fairy often, $2=$ sometimes, $3=$ almost never, $4=$ never). Examples of items are "In the last month, how often have you been upset because of something the happened unexpectedly?", "In the last month, how often have you felt nervous and stressed", and "In the last month, how often have you felt that things were going your way?". PSS-10 demonstrated good internal consistency reliability and validity, the
} 
Cronbach's alpha correlation coefficient was 0.78 (Cohen \& Williamson, 1988). In another study conducted by Lesage, Berjot and Deschamps (2012), the Cronbach's alpha correlation coefficient was 0.83. In this study, the Cronbach's Alpha for the scale was 0.78.

\section{Data Analysis}

Data was collected and analysed using Statistical Package for the Social Sciences (SPSS) software version 21.0 based on the research objectives and hypotheses. The antecedent variables in the current study comprised of student background (age, sex and years of education) and parent background (age, years of education and monthly income). The independent variables were parental attachment and stress. In line with the objectives, all the variables were tested on dependent variable (i.e. stress) to determine the correlations and differences. An exploratory data analysis (EDA) was done to make sure all the variables in this study are normally distributed before conducting more complex analyses procedures.

Two types of statistical analysis were utilized, which were descriptive statistics and inferential statistics. Descriptive statistics was used to interpret data in the form of frequency distribution, central tendency and dispersion. As for inferential statistics, it was used to test the hypotheses and to infer from sample (statistics) to population (parameter). Three types of inferential statistics were used to analyse the collected data, which pearson product-moment correlation, independent samples t-test and multiple regression.

\section{Results}

\section{Family Background}

The findings of parent background showed that most of the respondents' fathers were aged 60 years old and above (38.00\%) while the least of the respondents' fathers were aged 55 to 59 years old $(27.00 \%)$. The average of father's age was 57.48 years old with standard deviation of 6.74. On the other hand, it was found that most of the respondents' mothers were aged 55 years old and above $(44.00 \%)$, while the least of the respondents' mothers were aged 51 to 54 years old $(19.00 \%)$. The average of mother's age was 53.51 years old with standard deviation of 6.25. Moreover, it was found that a considerable proportion of respondents' fathers $(79.80 \%)$ and respondents' mothers $(82.80 \%)$ received education at least up to secondary level. The average years of education for both fathers and mothers were 10.61 years and 9.90 years respectively. For parent's monthly income, it was discovered that most of the respondents' fathers $(40.00 \%)$ were in the lower monthly income group, which was RM 3000 and below; while majority of the respondents' mothers $(84.00 \%)$ were in the lower monthly income group, which was RM 2000 and below. In terms of employment status, most of the respondents' fathers $(44.50 \%$ were working in non-government organization, while only $5.00 \%$ of fathers were homemaker. There were $32.30 \%$ and $18.30 \%$ of respondents' fathers were self-employed and working in government sector respectively. Most of respondents' mothers $(63.80 \%)$ were homemaker, whereas only $3.00 \%$ of mothers were working in government sector. There were $21.00 \%$ of respondents' mothers were working in nongovernment organization and $12.30 \%$ of mothers were self-employed.

\section{Relationship between Undergraduates Students Background and Parents Background with Stress}

Based on Table 1, the finding revealed that there was a significant relationship between age and stress $(r=-0.14, p<0.01)$. This showed that when there was an increase in the age of students, the stress level experienced by them would decrease. As shown in Table 1, there was no significant relationship between respondent's years of education and stress $(r=-0.09, p>$ 
Table 1: Correlation Matrix for Student Background, Parent Background, Parental Attachment, Smartphone Addiction and Stress

\begin{tabular}{|c|c|c|c|c|c|c|c|c|c|c|c|c|}
\hline Variable & 1 & 2 & 3 & 4 & 5 & 6 & 7 & 8 & 9 & 10 & 11 & 12 \\
\hline 1. Respondent's Age & 1 & & & & & & & & & & & \\
\hline $\begin{array}{c}\text { 2. Respondent's } \\
\text { Years of } \\
\text { Education }\end{array}$ & $0.54 * *$ & 1 & & & & & & & & & & \\
\hline 3. Father's Age & $0.36 * *$ & $0.26 * *$ & 1 & & & & & & & & & \\
\hline 4. Mother's Age & $0.45 * *$ & $0.35 * *$ & $0.88 * *$ & 1 & & & & & & & & \\
\hline $\begin{array}{c}\text { 5. Father's Years of } \\
\text { Education }\end{array}$ & 0.05 & 0.02 & 0.01 & 0.04 & 1 & & & & & & & \\
\hline $\begin{array}{c}\text { 6. Mother's Years of } \\
\text { Education }\end{array}$ & -0.01 & 0.05 & $-0.21 * *$ & $-0.16 * *$ & $0.65^{* *}$ & 1 & & & & & & \\
\hline $\begin{array}{l}\text { 7. Father's Monthly } \\
\text { Income }\end{array}$ & $-0.14 * *$ & 0.00 & $-0.37 * *$ & $-0.36 * *$ & $0.14 * *$ & $0.16^{* *}$ & 1 & & & & & \\
\hline $\begin{array}{l}\text { 8. Mother's Monthly } \\
\text { Income }\end{array}$ & $0.11 *$ & $0.10^{*}$ & -0.05 & -0.02 & -0.04 & $0.20 * *$ & 0.00 & 1 & & & & \\
\hline $\begin{array}{l}\text { 9. Mother } \\
\text { Attachment }\end{array}$ & -0.00 & -0.01 & $-0.17 * *$ & -0.01 & $0.12 *$ & 0.09 & $0.12 *$ & -0.08 & 1 & & & \\
\hline $\begin{array}{l}\text { 10. Father } \\
\text { Attachment }\end{array}$ & 0.06 & $0.10 *$ & -0.02 & -0.01 & $0.12 *$ & 0.04 & $-0.14 * *$ & -0.01 & $0.42 * *$ & 1 & & \\
\hline $\begin{array}{l}\text { 11. Smartphone } \\
\text { Addiction }\end{array}$ & $-0.17 * *$ & $-0.20 * *$ & -0.01 & $-0.11 *$ & 0.06 & 0.08 & 0.02 & $-0.17 * *$ & $-0.20 * *$ & $-0.28 * *$ & 1 & \\
\hline 12. Stress & $-0.14^{* *}$ & -0.09 & $-0.11^{*}$ & $-0.13 * *$ & -0.05 & -0.05 & $0.18^{* *}$ & $-0.14 * *$ & $-0.23 * *$ & $-0.48 * *$ & $0.54 * *$ & 1 \\
\hline
\end{tabular}

Note: $* \mathrm{p}<0.05, * * \mathrm{p}<0.01$ 
0.05). This could be explained that the years of education, regardless year 1, year 2, year 3 or year 4 , had no effect on the stress level of students.

The results showed that there was a significant relationship between father's age and stress $(\mathrm{r}=-0.11, \mathrm{p}<0.05)$. Similarly, the finding revealed that mother's age was significantly correlated with stress $(\mathrm{r}=-0.13, \mathrm{p}<0.01)$. This showed that when there was an increase in father's age and mother's age, the stress level experienced by students would decrease. Past research revealed that there was lack of information especially for the relationship between father's age and mother's age with stress. Father's years of education and mother's years of education were not significantly correlated with stress. Based on to Table 1, there was a significant relationship between father's monthly income and stress $(r=0.18, p<0.01)$. In other words, when there was an increase in father's monthly income, the stress level experienced by students would increase. The finding also revealed that there was a significant relationship between mother's monthly income and stress $(r=-0.14, p<0.01)$. This showed that when there was an increase in mother's monthly income, the stress level experienced by students would decrease.

\section{Relationships between Parental Attachment, Smartphone Addiction and Stress}

The results revealed that there were a significant relationship between mother attachment $(\mathrm{r}=-0.23, \mathrm{p}<0.01)$ and father attachment $(\mathrm{r}=-0.48, \mathrm{p}<0.01)$ with stress. Similarly, there was a significant relationship between smartphone addiction and stress $(r=0.54, p<0.01)$.

\section{Difference in Smartphone Addiction and Stress among Male and Female Undergraduate Students}

Independent sample T-test was conducted to test the significant difference in smartphone addiction and stress among male and female undergraduate students. As shown in Table 2, the mean of smartphone addiction among male undergraduate students was 33.61 while the mean of smartphone addiction among female undergraduate students was 36.33 . This showed that smartphone addiction among male was slightly higher than female. The results revealed that there was no significant difference in smartphone addiction between male and female undergraduate students, with $\mathrm{p}=0.30, \mathrm{t}=-2.94$.

The mean of stress among male undergraduate students was 20.91 while the mean of stress among female undergraduate students was 20.88. This showed that stress among male was slightly higher than female. However, the results revealed that there was no significant difference in stress between male and female undergraduate students, with $\mathrm{p}=0.96, \mathrm{t}=0.05$. 
Table 2: Difference in Smartphone Addiction and Stress among Male and Female Undergraduate Students

\begin{tabular}{|c|c|c|c|c|}
\hline \multirow{4}{*}{ Variable } & \multicolumn{2}{|c|}{ Sex } & \multirow{4}{*}{$t$} & \multirow{4}{*}{$\mathrm{p}$} \\
\hline & & & & \\
\hline & \multicolumn{2}{|c|}{ Mean } & & \\
\hline & Male & Female & & \\
\hline Smartphone Addiction & 33.61 & 36.33 & -2.94 & 0.30 \\
\hline Stress & 20.91 & 20.88 & 0.05 & 0.96 \\
\hline
\end{tabular}

\section{Predictors of Undergraduate Students' Stress}

Based on results from Table 3, the overall model was significant with a $\mathrm{R}^{2}$ of 0.44 . This model explained $44.00 \%$ of the variance towards stress score with $\mathrm{F}=29.11, \mathrm{p}<0.001$. The results showed that father's age, mother's years of education, father's monthly income, father attachment and smartphone addiction were significant predictors of stress among undergraduate students.

It was revealed that smartphone addiction had the highest Beta Coefficient, which showed that it was the most important variable that influenced the stress of undergraduate students $(\beta$ $=0.45, \mathrm{p}<0.001)$. This followed by father attachment $(\beta=-0.34, \mathrm{p}<0.001)$, father's age $(\beta$ $=-0.18, p<0.05)$, mother's years of education $(\beta=-0.12, p<0.05)$ and father's monthly income $(\beta=0.10, p<0.05)$. This indicated that smartphone addiction was the strongest unique predictor among other variables.

Table 3: Multiple Regression Analysis for Stress

\begin{tabular}{lccc}
\hline \multicolumn{1}{c}{ Variable } & \multicolumn{3}{c}{ Stress } \\
\cline { 2 - 4 } & $\mathrm{B}$ & $\beta$ & $\mathrm{p}$ \\
\hline Student Background & & & \\
Age & -0.14 & -0.04 & 0.43 \\
Years of education & 0.42 & 0.08 & 0.07 \\
Parent Background & & & \\
Father's age & -0.15 & $-0.18^{*}$ & 0.04 \\
Mother's age & 0.07 & 0.07 & 0.42 \\
Father's years of education & 0.05 & 0.03 & 0.55 \\
Mother's years of education & -0.25 & $-0.12^{*}$ & 0.03 \\
Father's monthly income & 0.00 & $0.10^{*}$ & 0.02 \\
$\quad$ Mother's monthly income & 0.00 & -0.06 & 0.16 \\
Parental Attachment & & & \\
Mother attachment & -0.02 & -0.04 & 0.40 \\
Father attachment & -0.11 & $-0.34 * * *$ & 0.00 \\
Smartphone Addiction & 0.29 & $0.45^{* * *}$ & 0.00 \\
$\mathrm{R}^{2}=$ 0.44 & & & \\
F = 29.11 & & & \\
\hline Note: *p $<0.05, * * * p<0.001, \beta=$ Beta Coefficient & & & \\
\hline
\end{tabular}




\section{Discussion and Conclusion}

Every individual experiences stress regardless of age, occupation, social status, race or cultural background. For a student, stress may be caused by academic pressure, financial problems, health problems or loss of a family member or close friend. Stress will affect the ability of students to face problems and has the potential to either induce or interfere with their studies (Rathakrishnan, Molugulu, Parasuraman, \& Narasappa, 2012). Excessive stress affects physical and mental health problems, reduces self-esteem, causes depression and impacts a student's academic achievement, personal and professional development (Yusoff et al., 2010).

A lot of factors that may contribute to stress among undergraduate students. The results of this study showed that high level of smartphone addiction tend to increase stress experienced by undergraduate students. This finding was in line with previous researches that indicated smartphone use was associated with increased stress (Thomée et al., 2011; Yun, et al., 2012).

As expected low level of mother attachment and father attachment, the stress level experienced by students would decrease. These findings were compatible with past researches that showed that there was a negative relationship between attachment and stress (Howard \& Medway, 2004; Vogel \& Wei, 2005; McCarthy et al., 2006). Secure attachment was associated with lower levels of stress symptoms and stress-produced emotions than insecure attachment (McCarthy et al., 2006).

The results revealed that there was no significant difference in smartphone addiction and stress between male and female of undergraduate students. This finding was consistent with past studies which found that there was no significant difference between male and female students on the addiction of mobile phone (Nassehi et al., 2016; Sahin et al., 2013, Bianchi \& Philips, 2005). While, this finding was inconsistent with previous studies which stated that female students experienced a higher overall level of stress than male students (Brougham et al., 2009; Dusselier et al., 2005).

It is unavoidable that this study has some limitations. Firstly, the population of this study only include the university students in UPM, therefore the findings of the study could only be generalized in this particular population. In order to have better understanding, studies on larger sample size and diverse demographics of the sample should be carried out. This will allow the effects of parental attachment and smartphone addiction on stress among university students to be understand more thoroughly.

The gender aspects of parental attachment, smartphone addiction and stress can be examined by obtaining larger sample size so that the concept of parental attachment, smartphone addiction and their impacts on stress among university students can be understand well. Moreover, this study only emphasize on the variables of students background and parent background which associated with parental attachment, smartphone addiction and stress among undergraduate students in UPM.

Therefore, future researches are suggested to involve other variables like peer and school context or in varying contexts. This will enable a comprehensive investigation of how parental attachment and smartphone addiction affect stress among university students. Next, the current study is a cross-sectional research so it is unable to identify the direction of 
effects. In order to clarify such concerns, longitudinal research is suggested so that the causal effects can be longitudinally verified. It should explore the relation between parental attachment, smartphone addiction and stress among university students for a period of time.

Lastly, as this study used a self-report method in data collection, the willingness and honesty of respondents in answering the provided questionnaire will affect the accuracy of the results. The answers given on the questionnaires may be self-biased, which will hinder the optimal response rates of this study. In conclusion, this study found that parental attachment and smart addiction influence stress among undergraduate students.

\section{References}

Ahmadi, A., Mustaffa, M. S., Haghdoost, A. A., \& Alavi, M. (2014). Mindfulness and Related Factors among Undergraduate Students. Procedia - Social and Behavioral Sciences, 159, 20-24.

Alavi, S. S., Ferdosi, M., Jannatifard, F., Eslami, M., Alaghemandan, H., \& Setare, M. (2012). Behavioral Addiction versus Substance Addiction: Correspondence of Psychiatric and Psychological Views. International journal of preventive medicine, 3(4), 290-4.

Armsden, G. C., \& Greenberg, M. T. (1987).The Inventory of Parent and Peer Attachment: Individual Differences and Their Relationship to Psychological Well-being in Adolescence. Journal of Youth and Adolescence, 16(5), 427-454.

Andone, T., Błaszkiewicz, K., Eibes, M., Trendafilov, B., Montag, C., \& Markowetz, A. (2016). How Age and Gender Affect Smartphone Usage. doi:10.1145/2968219.2971451.

Balakrishnan, V., \& Raj, R. G. (2012). Exploring the relationship between urbanized Malaysian youth and their mobile phones: A quantitative approach. Telematics and Informatics, 29(3), 263-272.

Bianchi, A., \& Phillips, J. G. (2005). Psychological predictors of problem mobile use. CyberPsychology \& Behavior, 8(1), 39-51.

Brougham, R. R., Zail, C. M., Mendoza, C. M., \& Miller, J. R. (2009). Stress, sex differences, and coping strategies among college students. Current Psychology, 28(2), 85-97.

Cohen, S., \& Williamson, G. (1988). Perceived stress in a probability sample of the U.S. In S. Spacapam \& S. Oskamp (Eds.), The social psychology of health: Claremont Symposium on Applied Social Psychology. Newbury Park, CA: Sage.

Dogan, D., Gur, K., Sener, N., \& Cetindag, Z. (2012). The ways of handling stress and the attachment forms to parents of university students. Procedia-Social and Behavioral Sciences, 47, 470-476.

Dusselier, L., Dunn, B., Wang, Y., Shelley, M. C. II, \& Whalen, D. F. (2005). Personal, health, academic, and environmental predictors of stress for residence hall students. Journal of American College Health, 54(1), 15-24.

D'Zurilla, T. J., \& Sheddy, C. F. (1991). Relation between social problem-solving ability and subsequent level of psychological stress in college students. Journal of Personality and Psychology, 61(5), 841-846.

Elhai, J. D., Levine, J. C., Dvorak, R. D., \& Hall, B. J. (2017). Non-social features of smartphone use are most related to depression, anxiety and problematic smartphone use. Computers in Human Behavior, 69, 75-82.

Hakoama, M., \& Hakoyama, S. (2011). The impact of cell phone use on social networking and development among college students. The American Association of Behavioral and Social Sciences Journal, 15, 1-20. 
Howard, M. S., \& Medway, F. J. (2004). Adolescents' Attachment and Coping With Stress. Psychology in the Schools, 41(3), 391-402.

Jeong, S. H., Kim, H., Yum, J. Y., \& Hwang, Y. (2016) What type of content are smartphone users addicted to?: SNS vs. games. Computers in Human Behavior, 54, 10-17.

Kline, S. L., \& Liu, F. (2005). The influence of comparative media use on acculturation, acculturative stress, and family relationships of Chinese international students. International Journal of Intercultural Relations, 4(29), 367-390.

Kwon, M., Kim, D., Cho, H., \& Yang, S. (2013). The Smartphone Addiction Scale: Development and Validation of a Short Version for Adolescents. Plos ONE, 8(12), e83558. http://dx.doi.org/10.1371/journal.pone.0083558

Lesage, F., Berjot, S., \& Deschamps, F. (2012). Psychometric properties of the French versions of the perceived stress scale. International Journal of Occupational Medicine and Environmental Health, 25(2), 178-184.

Lopez-Fernandez, O. (2017). Short version of the Smartphone Addiction Scale adapted to Spanish and French: Towards a cross-cultural research in problematic mobile phone use. Addictive Behaviors, 64, 275-280. http://dx.doi.org/10.1016/j.addbeh.2015.11.013

Matud, M. P. (2004). Gender differences in stress and coping styles. Personality and Individual Differences, 37, 1401-1415.

McCarthy, C. J., Lambert, R. G., \& Moller, N. P. (2006). Preventive resources and emotion regulation expectancies as mediators between attachment and college students' stress outcomes. International Journal of Stress Management, 13(1), 1-22.

Murdock, K. K. (2013). Texting while stressed: Implications for students 'burnout, sleep, and well-being. Psychology of Popular Media Culture, 2, 207-221.

Nassehi, A., Arbabisarjou, A., Jafari, M., Ghasemi, M., \& Najafi, K. (2016). Surveying the relationship of Internet Addiction with dependence on cell phone, depression, anxiety, and stress in collegians. International Journal of Advanced Biotechnology and Research, 7(3), 2267-2274.

Niemi, P.M., \& Vainiomaki, P.T. (1999). Medical Students' Academic Distress, Coping and Achievement Strategies during the Pre-Clinical Years. Teaching and Learning in Medicine, 11(3), 125-134.

Noyan, C., Darcin, A., Nurmedov, S., Yilmaz, O., \& Dilbaz, N. (2015). Validity and reliability of the Turkish version of the Smartphone Addiction Scale-Short Version among university students. Anatolian Journal of Psychiatry, 16, 73. http://dx.doi.org/10.5455/apd.176101

Othman, C. N., Farooqui, M., Yusoff, M. S. B., \& Adawiyah, R. (2013). Nature of stress among health science students in a Malaysian University. Procedia-Social and Behavioral Sciences, 105, 249-257.

Oxford Dictionaries. (n.d.). Retrieved from https://en.oxforddictionaries.com/ definition/smartphone

Rabbani, M., Kasmaienezhadfard, S., \& Pourrajab, M. (2014). The Relationship between Parental Attachment and Stress: A Review of Literatures Related to Stress among Students. Journal of Counseling Psychology, 3(1), 42-50.

Rathakrishnan, B., Molugulu, N., Parasuraman, B., \& Narasappa, K. (2012). The Relationship of Stress, Alcoholism and Sexual Behavior with Mental Health among Secondary School Students: A Study in Sabah, Malaysia. European Journal of Social Sciences, 31(3), 376-383.

Roberts, J. A., \& Pirog III, S. F. (2012). A preliminary investigation of materialism and impulsiveness as predictors of technological addictions among young adults. Journal of Behavioral Addictions, 2(1), 56-62. 
Roberts, J., Yaya, L., \& Manolis, C. (2014). The invisible addiction: Cell-phone activities and addiction among male and female college students. Journal of Behavioral Addictions, 3(4), 254-265.

Sahin, S., Ozdemir, K., Unsal, A., \& Temiz, N. (2013). Evaluation of mobile phone addiction level and sleep quality in university students. Pakistan Journal Medical Science, 29(4), 913-918.

Schnyders, C. (2012). Parental and Peer Attachment as Predictors of the Degree of Experiencing Emerging Adulthood among Undergraduates between the ages of 18-20: A Standard Multiple Regression Study. Lifespan Development and Educational Sciences.

Thomas, D. (2016). Cellphone Addiction and Academic Stress among University Students in Thailand. International Forum, 19(2), 80-96.

Radeef, A.S., Faisal, G. G., Ali, S. M., \& Ismail M. K. (2014). Source of Stressors and Emotional Disturbances among Undergraduate Science Students in Malaysia. International Journal of Medical Research and Health Sciences, 3(2), 401-410.

Ramli, N. H., Alavi, M., Mehrinezhad, S. A., \& Ahmadi, A. (2018). Academic Stress and Self-Regulation among University Students in Malaysia: Mediator Role of Mindfulness. Behavioral Science, 8(1), 12-20.

The American Institute of Stress. (2017).What is Stress? Retrieved from https://www.stress.org/daily-life/

Thomée, S., Dellve, L., Härenstam, A., \& Hagberg, M. (2010). Perceived connections between information and communication technology use and mental symptoms among young adults-A qualitative study. BMC Public Health, 10, 1-14.

Thomée, S., Härenstam, A., \& Hagberg, M. (2011). Mobile phone use and stress, sleep disturbances, and symptoms of depression among young adults - A prospective cohort study. BMC Public Health, 11, 66.

Toda, M., Ezoe, S., \& Takeshita, T. (2014). Mobile phone use and stress-coping strategies of medical students. International Journal of Cyber Behavior, Psychology and Learning, 4(4), 41-46.

Vahedi, Z., \& Saiphoo, A. (2018). The association between smartphone use, stress, and anxiety: A meta-analytic review. Stress and Health, 34(1), 1-12.

Van Deursen, A. J., Bolle, C. L., Hegner, S. M., \& Kommers, P. A. (2015). Modeling habitual and addictive smartphone behavior: The role of smartphone usage types, emotional intelligence, social stress, self-regulation, age, and gender. Computers in human behavior, 45, 411-420.

Vogel, D. L., \& Wei, M. (2005). Adult Attachment and Help-Seeking Intent: The Mediating Roles of Psychological Distress and Perceived Social Support. Journal of Counseling Psychology, 52(3), 347.

Wang, J. L., Wang, H. Z., Gaskin, J., \& Wang, L. H. (2015). The role of stress and motivation in problematic smartphone use among college students. Computers in Human Behavior, 53, 181-188.

Yun, H., Kettinger, W. J., \& Lee, C. C. (2012). A new open door: The smartphone's impact on work-to-life conflict, stress, and resistance. International Journal of Electronic Commerce, 16(4), 121-151.

Yusoff, M. S. B., Ahmad Hamid, A. H., Rosli, N. R., Zakaria, N. A., Che Rameli, N. A., Abdul Rahman, N. S., . . Abdul Rahman, A. (2010). Prevalence of stress, stressors and coping strategies among secondary school students in Kota Bharu, Kelantan, Malaysia. International Journal of Students' Research, 1(1), 23-28. 
Zhang, Y. L., Zhang, Y. L., Zhang, Y. X., Wang, J. L., \& Hung, C. Y. (2011). Reliability and validity of Chinese version of Revised Inventory of Parent and Peer Attachment in junior students. Chinese Mental Health Journal, 25(1), 66-70. 